\title{
Synthesis, Characterization and Biological Active 2 (Dimethylamino) Cyclohexane-1, 3-Dione \\ Veerappan Jeyachandran
}

Department of Chemistry, Bharath Institute of Higher Education and Research, Selaiyur, Chennai, Tamil Nadu, India

Corresponding author e-mail: jeyorg@gmail.com

\section{ABSTRACT}

\section{Article Info}

Volume 8, Issue 1

Page Number: 07-09

Publication Issue :

January-February-2021

Article History

Accepted : 01 Jan 2021

Published : 04 Jan 2021
In the present work, the precursors 2- ( ( dimethylamino ) methylene ) cyclohexane-1,3-dione 4 and 2- ( (dimethylamino ) methylene ) -5, 5dimethylcyclohexane-1,3-dione 5 were synthesized from the reaction of 1,3cyclohexanedione 1 or 5,5-dimethyl-1,3-cyclohexandione 2 with DMF-DMA 3, respectively following literature procedure (Scheme 1).

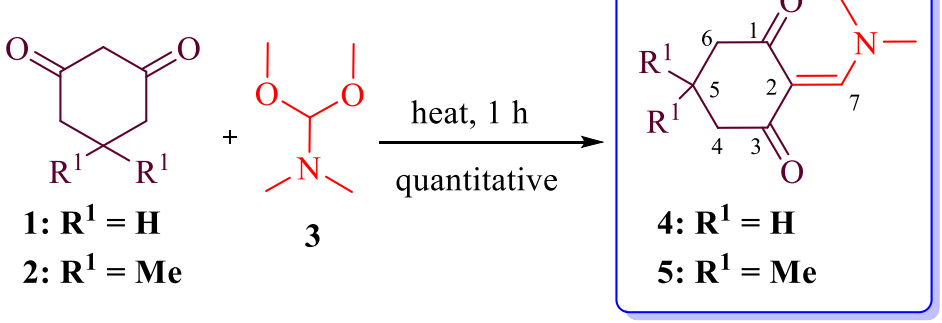

Seheme 1. Synthesis of precursors 4, 5

Keywords : Pyrazoles, Dimethylamino, Cyclohexane and Alkaloids.

\section{INTRODUCTION}

Pyrazoles are five-member ring heterocyclic compounds, consisting of a doubly unsaturated five membered ring with two adjacent nitrogen atoms and are also called as azoles. These are aromatic molecules due to their planar conjugated ring structures with six delocalized $\pi$-electrons [1]. The term pyrazole was given by Ludwig Knorr in 1883. Being so composed and having pharmacological effects on humans, they are classified as alkaloids, although they are rare in nature. In 1959, the first natural pyrazole, $\beta-[1-$ pyrazolyl] alanine was isolated from the seeds of water melons [Citurllus lanatus] [2]. Literature survey has revealed that till 1930s very little had been done for the synthesis of steroidal pyrazole derivatives. Several pyrazole derivatives have been found to possess significant activities such as $5-\alpha$ reductase inhibitor, [3] antiproliferative, [4] antiparasitiC [5] and herbicides [6].

pyrazolo[1,5-a] quinoline derivatives have been developed for dopamine D4 antagonist agents,[7] GPR109a agonist agents [8] and organic light- 
emitting devices [9]. However, besides these examples, the pyrazolo[1,5-a] quinoline subunit has not been applied to seek further biologically and materially active[10] compounds, which might be due to the lack of general methods for the synthesis of pyrazolo[1,5-a] quinoline derivatives [11].

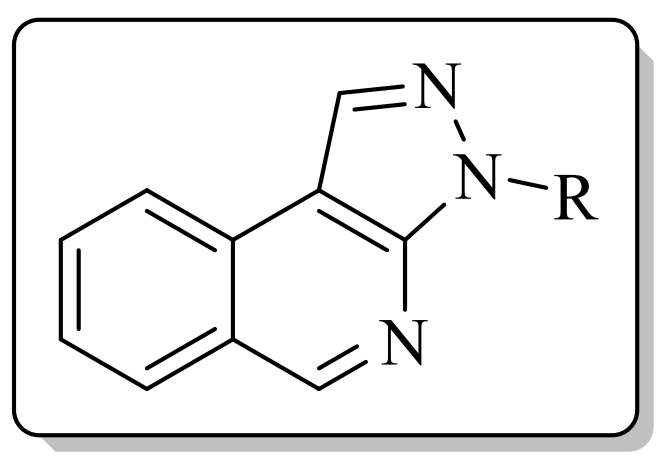

Figure 1.

\section{General procedure for the synthesis of 4 or 5}

A mixture of cyclic 1,3-diketone 1 or 2 (1 mmol) and $N, N$-dimethylformamide dimethyl acetal 3 (1.5 mmol) was heated to reflux. After 1 hour of continuous reflux the solvent was removed under reduced pressure. The reaction mass upon cooling to room temperature afforded $\mathbf{4}$ or $\mathbf{5}$ as brown crystals, which was used for next step without further purification.

\section{2-((Dimethylamino)methylene) cyclohexane-1,3- dione (4)}

Brown crystals; Yield 99\%; m.p. 85-86 ${ }^{\circ} \mathrm{C} ;{ }^{1} \mathrm{H}$ NMR (300 MHz, $\mathrm{CDCl}_{3}$ ) $\delta_{\text {н: }} 1.95$ (qui, $J=6.4 \mathrm{~Hz}, 2 \mathrm{H}$ ), 2.47 (t, $J=6.5 \mathrm{~Hz}, 4 \mathrm{H}), 3.18$ (s, 3H), $3.40(\mathrm{~s}, 3 \mathrm{H}), 8.06$ (s, $1 \mathrm{H}) \mathrm{ppm} ;{ }^{13} \mathrm{C} \mathrm{NMR}\left(75 \mathrm{MHz}, \mathrm{CDCl}_{3}\right) \delta_{\mathrm{c}:} 19.3,37.9$, 44.4, 48.3, 109.1, 162.0, 195.9 ppm.

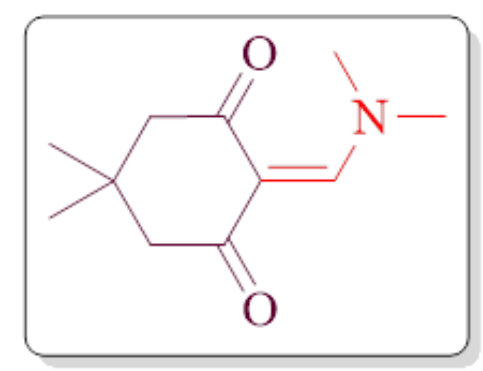

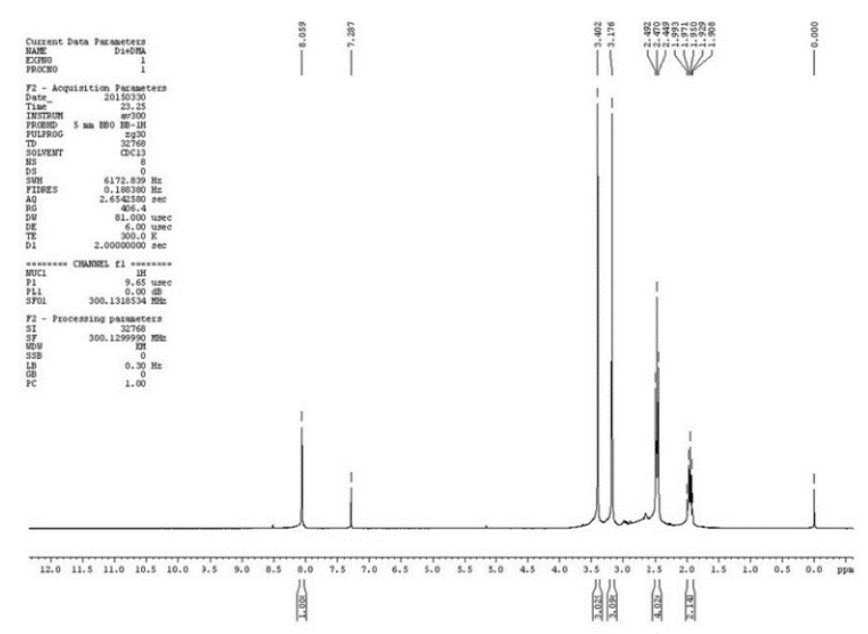

Figure 21. ${ }^{1} \mathrm{HNMR}$ spectrum of $\mathbf{4}$

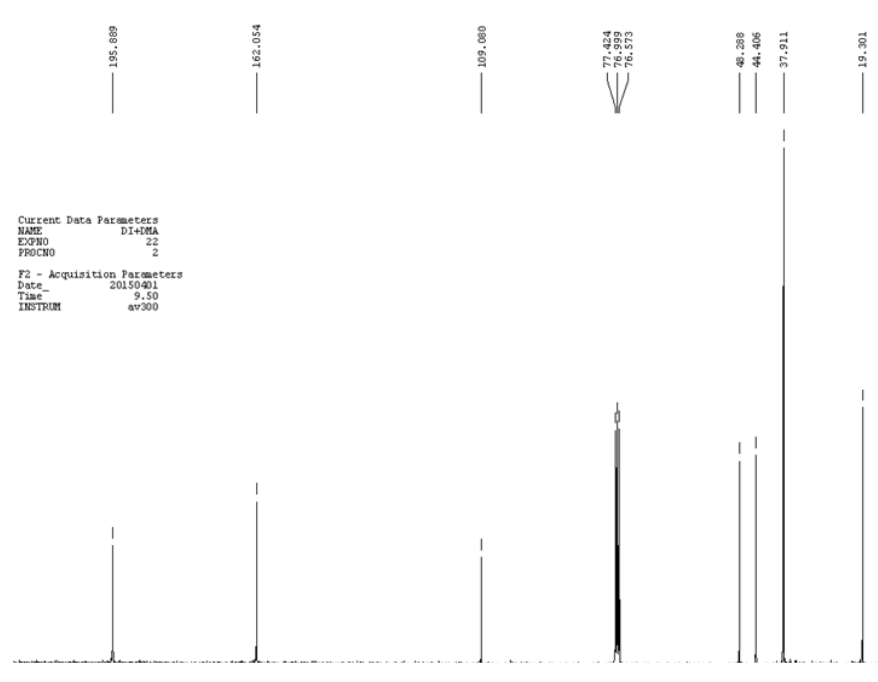

Figure 22. ${ }^{13} \mathrm{CNMR}$ spectrum of 4

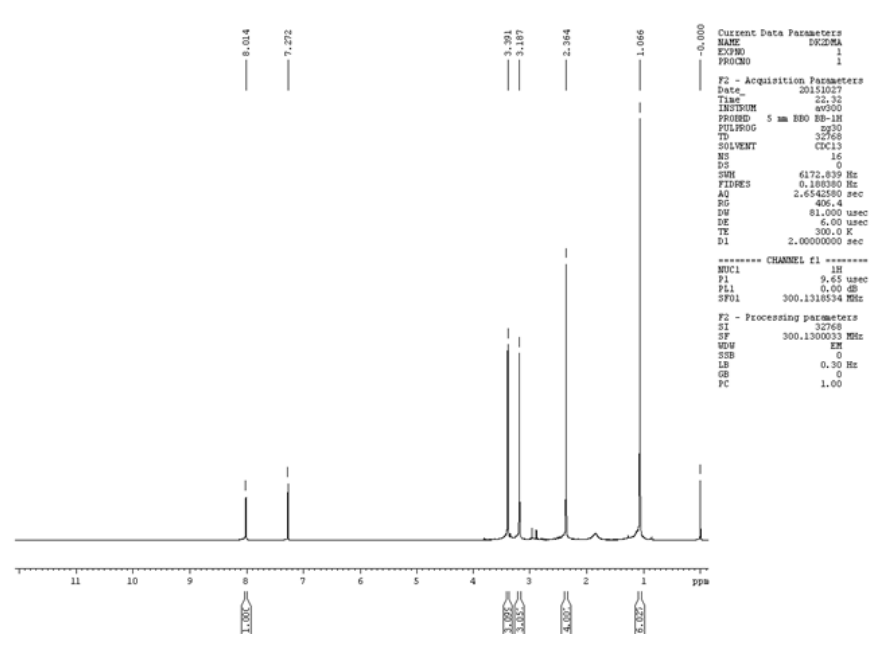

Figure 23. ${ }^{1} \mathrm{HNMR}$ spectrum of 5 


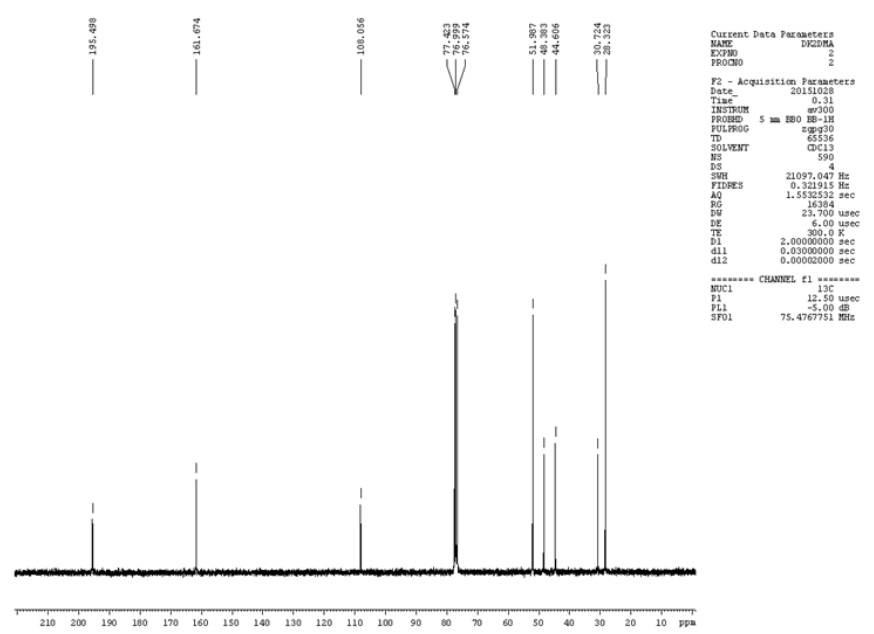

Figure 24. ${ }^{13} \mathrm{CNMR}$ spectrum of 5

\section{CONFLICT OF INTEREST}

The authors declare no conflict of interest.

\section{ACKNOWLEDGMENTS}

The encouragement and support from Bharath University, Chennai is gratefully acknowledged. For provided the laboratory facilities to carry out the research work.

\section{REFERENCES}

[1]. Eicher, T.; Hauptmann, S. Edition IInd, WileyVCH, 2003, ISBN 3527307206.

[2]. Nimbalkar, S.; Hote, S. V. Int. J. Rec. Innovation Trends in Comp. Comm., 2015, 3, 61.

[3]. Amr, A. G.; Abdel-Latif, N. A.; Abdlla, M. M. Acta Pharm., 2006, 56, 1203.

[4]. Chimichi, S.; Boccalini, M.; Hassan, M.M.M.; Viola, G.; Acqua, F. D.; Curini, M. Tetrahedron,2006, 62, 90.

[5]. Kobayashi, Hisafumi, Kato, Motto; Nitani, Fumio, Chem. Abstr., 1989, 106 297008/g.

[6]. Henry, T.A.; The Plant Alkoloids, Anmol Publicaion Pvt. Ltd., 1999.

[7]. Dzvinchuk. I. B.; Tolmachova. N. A.; Chernega. A. N.; Lozinskii. M. O. Chem. Heterocycl. Compd., 2009, 45, 194.
[8]. Toche, R. B.; Bhavsar, R. B.; Kazi, M. A.; Bagul, S. M.; Jachak, M. N. J. Heterocycl. Chem., 2010, 47, 287

[9]. Liqiang, Wu.; Yang, L.; Yan, F.; Yang, C.; Fang, L. Bull. Korean Chem. Soc., 2010, 31, 1051.

[10]. Liqiang, Wu.; Suying, Ma.; Yan, F.; Yang, C. Monatsh. Chem., 2010, 141, 565.

[11]. Jiang, B.;Zhang, G.;Ning, Ma.;Shi, F.;Tu, S. J.;Kaur,P.; Li, G. Org. Biomol. Chem.,2011, 9, 3834.

\section{Cite this article as :}

Veerappan Jeyachandran, "Synthesis,

Characterization and Biological Active 2

(Dimethylamino) Cyclohexane-1, 3-Dione", International Journal of Scientific Research in Science and Technology (IJSRST), Online ISSN : 2395-602X, Print ISSN : 2395-6011, Volume 8 Issue 1, pp. 07-09, January-February 2021. Available at doi : https://doi.org/10.32628/IJSRST207667 